\title{
Elektrodepozisyon Yapılan ZnO İnce Filmlerinin Korozyon Davranışı
}

\author{
Corrosion Behaviour of Electrodeposited ZnO Thin Films
}

\author{
Kübra ÇINAR DEMIR* \\ Atatürk Üniversitesi, Oltu Yerbilimleri Fakültesi, Maden Mühendisliği Bölümü, 25400 Erzurum
}

\begin{abstract}
• Geliş tarihi / Received: 09.09.2019 • Düzeltilerek geliş tarihi / Received in revised form: 29.01.2020 • Kabul tarihi / Accepted: 31.01 .2020
\end{abstract}
$\ddot{O} \mathbf{z}$

Elektrokimyasal büyütme metodu, homojen ince filmlerin oluşumunun mümkün olması, düşük maliyeti, nano-yapıların elde edilebilirliğinin kolaylı̆̆ı, büyük yüzey alanlı büyütmelerin gerçekleştirilebilirliği ve stokiyometrideki kontrolü gibi avantajlara sahip olması nedeniyle yaygın bir şekilde kullanılmaktadır. Bu çalışmada, nano-yapılı çinko oksit $(\mathrm{ZnO})$ ince filmler elektrokimyasal büyütme metodu kullanarak indiyum tin oksit (ITO) kaplı cam altlıklar üzerine büyütülmüştür. Filmlerin kalitesi üzerine katodik potansiyel, zaman, sıcaklık ve pH etkileri analiz edilmiştir. $\mathrm{ZnO}$ ince filmler dimetil sülfoksit'te (DMSO) $130{ }^{\circ} \mathrm{C}$ sicaklıkta 3600 sn büyütme süresinde-1.0 V katodik potansiyelde elde edilmiştir. X-ışını kırınımı (XRD) analizi, ZnO ince filmlerin açıç̧a (0002) tercihi yöneliminde tek kristal özelliğe sahip olduğunu doğrulamaktadır. Soğurma ölçümlerine göre, $\mathrm{ZnO}$ filminin optik band aralığı (Eg) $3.4 \mathrm{eV}$ olarak hesaplanmıştır. ITO altlık üzerine elektrodepozisyon yapılan $\mathrm{ZnO}$ ince filmlerin korozyon özellikleri elektrokimyasal empedans spektroskopisi (EIS) ve Tafel ölçümleriyle incelenmiştir. Nyquist, açık devre potansiyeli (OCV) ve Bode analizi ZnO'nun yapısal değişimini ve korozyon davranışını anlamak için oluştutulmuş ve Nyquist eğrisine fit yapılarak elde edilen çözelti direnci (Rs), polarizasyon direnci (Rp), sabit faz elementi $\left(\mathrm{CPE}_{\mathrm{dl}}\right)$ ve sabit faz elementi üstel değeri (n) sırasıyla $49.61 \Omega, 4.97 \times 10^{-6} \Omega, 6.75 \times 10-6 \Omega^{-1} . \mathrm{s}^{\mathrm{c}} \mathrm{cm}^{-2}$ ve 0.940 olarak hesaplanmıştır. Tafel eğrisine fit yapılarak elde edilen korozyon potansiyeli $\left(\mathrm{E}_{\mathrm{kor}}\right)$ ve korozyon akımı $\left(\mathrm{I}_{\mathrm{kor}}\right)$ sırasıyla-0.199 V ve $2.97 \times 10^{-8}$ A olarak elde edilmiştir. Tüm ölçümler dikkate alındığında, büyük korozyon direncinin nedeninin büyütme sırasında oluşan kusurların artışına bağlı olarak yüzey pasivasyonuyla açıklanabilir.

Anahtar kelimeler: EIS, Elektrodepozisyon, Tafel, XRD, ZnO

\begin{abstract}
Electrochemical deposition method (ECD) has been widely used due to its advantages in stoichiometry control, large area growth, easy to form nano-structures, being low coast, possible formation of homogeneous thin films. In this study, nanostructured zinc oxide ( $\mathrm{ZnO}$ ) thin films were deposited on Indium tin oxide (ITO)-coated glass substrate using ECD. The effects of cathodic potential, time, temperature and $\mathrm{pH}$ on quality of the films were examined. ZnO thin films were achieved with in cathodic potential with $-1.0 \mathrm{~V}$ and deposition time with 3600 seconds at temperature $130^{\circ} \mathrm{C}$ in dimethyl sulfoxide (DMSO). X-ray diffraction (XRD) analysis confirmed clearly that the ZnO thin films have sinle crystalline properties with a strong c-axis (0002) preferential orientation. According to the absorption measurements, the optical bandgap of the ZnO film was calculated as Eg $3.4 \mathrm{eV}$. ZnO thin films electrodeposited on ITO substrate were studied with Electrochemical Impedance Spectroscopy (EIS) and Tafel measurements. Nyquist, open circuit potential and Bode analysis were evaluated to find out the structural changing of $\mathrm{ZnO}$ and its corrosion behavior. With the help of these plots, solution resistance $(R s)$, polarization resistance $(R p)$, a constant phase element $(C P E)$ and a CPE exponent (n) were calculated as $49.61 \Omega, 4.97 \times 10^{6} \Omega, 6.75 \times 10^{-6} \Omega^{-1}$. s.cm ${ }^{-2}, 0.940$, respectively. Also, we examined the $\mathrm{ZnO}$ thin films corrosion features with the help of tafel measurements. Considering all these measurements, the possible reason of increasing corrosion resistance can be interpreted as surface passivation depending on increasing defects caused by deposition.
\end{abstract}

Keywords: EIS, Electrodeposition, Tafel, XRD, ZnO

*Kübra ÇINAR DEMIR; kubra.cinar@atauni.edu.tr, Tel: (0442) 816 5935, orcid.org/0000-0001-7528-3138 


\section{Giriş}

$\mathrm{ZnO}, 3.3$ ile $3.5 \mathrm{eV}$ arasında değişen direkt band aralıklı n-tipi bir yariiletkendir. ZnO'nun diğer geniş band aralıklı yariletkenlere göre en önemli avantajlarından biri de üç kat daha büyük eksiton bağlanma enerjisine sahip olmasıdır $(60 \mathrm{meV})$. Yarriletken teknolojisinde geniş bir uygulama alanına sahip olan $\mathrm{ZnO}$ bileşik yarıiletkeni, moleküler demet epitaksi (MBE) (Przezdziecka vd., 2019), radyo frekansı magnetron saçılma (RF magnetron sputtering) (Wittkamper vd., 2019), kimyasal buhar biriktirme (CVD) (Fay vd., 2005), sprey proliz (Tharsika vd., 2019), kimyasal banyo biriktirme (CBD) (Pellegrino vd., 2019) ve elektrodepozisyon (Pan vd., 2019; Pei vd., 2019; Sharma vd., 2019; Wang vd., 2019) gibi pek çok farklı teknikle büyütülmektedir.

Fahoume vd. (2006) ZnO ince filmlerini, çinko klorür kullanarak hazırlanan çözeltide ve hava akışının sürekli olduğu bir ortamda elektrodepozisyon işlemiyle hem indiyum kalay oksit kaplı cam altlıklar hem de bakır altlıklar üzerine büyüttüklerini açıklamışlardır. $\mathrm{ZnO}$ filmlerin yapisal ve morfolojisi üzerine $\mathrm{pH}$ etkisini araştırmışlar ve optimum şartlarını belirlemişlerdir. Ayrıca filmlerin büyütme kinetiklerini de incelemişlerdir. Asidik çözeltilerde $\mathrm{ZnO}$ büyütme hızının bazik bir çözeltiden daha hızlı olduğunu ortaya çıkarmışlardır. Filmlerin yapısını XRD, geçirimli elektron mikroskobu kullanılarak çalışmışlar ve XRD analizleriyle filmlerin $\mathrm{pH}: 4$ 'te hegzagonal krsital yapıya sahip polikristal olduğunu göstermişlerdir. ZnO'nun optik geçirgenliğinin değişen film kalınlığıyla azaldığını göstermiş ve optik enerji band aralığını $3.26 \mathrm{eV}$ olarak hesaplamışlardır (Fahoume vd., 2006).

Weng vd. (2005) ZnO ince filmleri indiyum kapl1 cam altlıklar üzerine $65^{\circ} \mathrm{C}$ 'de bir $\mathrm{Zn}\left(\mathrm{NO}_{3}\right)_{2}$ sulu çözeltisinde elektrodepozisyon yaparak büyüttüklerini açıklamışlardır. XRD çalışmaları da elde edilen $\mathrm{ZnO}$ filmlerin hegzagonal wurtzite yap1lı polikristal olduğunu göstermiştir. Uygulanan voltajlar, büyütme zamanı ve tavlama sıcaklığı gibi çeşitli çalışma koşulları kontrol edilmiş ve uygulanan şartlara göre $\mathrm{ZnO}$ filmler hemen hemen 180 nm'den 320 nm'ye kadar değişen tanecik büyüklüğüne sahip farklı morfolojiler sunduğu gözlenmiştir. Büyütmeler 0.9 ile $-1.0 \mathrm{~V}$ potansiyde yürütülmüştür. $\mathrm{ZnO}$ filmler kompakt ve homojen bir yapıda ve filmlerin geçirgenliğinin $500 \mathrm{~nm}$ 'de \% 95'e yakın olduğunu açıklamışlardır. Yine farklı şartlar altında büyütülen $\mathrm{ZnO}$ filmlerin band aralığındaki değişimleri de incelediklerini açıklamışlardır (Weng vd., 2005).

Gao vd. (2006) ZnO ince filmleri iletken altlıklar üzerine elektrokimyasal büyütme metoduyla hazırladıklarını açıklamışlardır. $\mathrm{ZnO}$ ince filmlerin oldukça şiddetli (002) yöneliminde hegzagonal wurtzite yapıya sahip olduğu ortaya çıkmıştır. Spesifik kristal morfolojisi, mevcut proses için kendine has özelliklerden biri olan oryantasyon eki modu vasitasıly büyütme mekanizmasına katkıda bulunabilir. Çünkü yüksek çözünürlüklü $\mathrm{AFM}$ görüntülerinde katlı yapı ortaya çıkmıştır. Filmin yüksek geçirgenlik özelliği gösterdiği ve $3.3 \mathrm{eV}$ optik bant aralığ enerjisine sahip olduğu açıklanmıştır. $\mathrm{N}_{2}$ ve $\mathrm{Ar}$ gazı ortamında tavlama sonrası, güçlü yeşil emisyon tek başına iyonize olmuş oksijen kusurlarının ortaya çıkışıyla ilişkili olduğu gözlenmiştir. Tavlama şartlarını optimize ederek emisyon şiddetinin oldukça iyileştirilmesiyle bu metodun $\mathrm{ZnO}$ yeşil fosforunun hazırlanması için kullanılan geleneksel metodun yerini almasinın umut verici olabileceği açıklanmıştır (Gao vd., 2006).

Taleb vd. (2019) ITO altlı üzerine elektrokimyasal olarak $-0.5 \mathrm{~V}$ ile $-0.8 \mathrm{~V}$ arasinda değişen farklı potansiyellerde büyüttükleri $\mathrm{ZnO}$ ince filmlerin kalıcı zayıf manyetik alandaki etkilerini incelemişlerdir. Büyütmeler SEM, EDX ve elektrokimyasal testlerle karakterize edilmiştir. Elde edilen sonuçlara göre, $-0.5 \mathrm{~V}$ altında magnetik alan varlığında kristal boyutunda artış ve $-0.8 \mathrm{~V}$ büyütme potansiyeli altında $\mathrm{ZnO}$ büyütmelerin büyük kristallerinin sayısında azalma gözlenmiştir. Bir hafta korozyondan sonra zayıf magnetik alan altında mevcut büyütmenin açık devre potansiyelinin, polarizasyon eğri parametrelerinin ve kristalografik parametrelerin değiştiği açıklanmıştır (Taleb vd., 2019).

Xie vd. (2011) $\mathrm{Cu}$ altlıklar üzerine radyo frekanslı magnetron saçtırma metoduyla amorf $\mathrm{Zn}$ ve $\mathrm{ZnO}$ ince filmleri hazırladıklarını ve XRD, SEM ve Raman spektroskopisi ile karakterize ettiklerini açıklamışlardır. İnce filmlerin elektrokimyasal performans1 galvanostatik dönüşüm ve dönüşümlü voltametri ile çalışılmıştır. Filmlerin, Li-iyon kimyasal difüzyon katsayıları galvanostatik aralıklı titrasyon tekniği ve elektrokimyasal empedans spektroskopiyle belirlenmiştir. Amorf $\mathrm{Zn}$ ve $\mathrm{ZnO}$ filmlerinin hemen hemen $10^{14}$ ten $10^{12}$ $\mathrm{cm}^{2} \mathrm{~s}^{-1}$ arasında değişen benzer difüzyon değerleri gösterdiğini açılamış ve benzer Li-iyon taşıma karakteristikleri hem galvanostatik aralıkl titrasyon tekniğiyle hem de elektrokimyasal 
empedans spektroskopiyle tekniğiyle belirlendiğini ifade etmişlerdir (Xie vd., 2011).

Kouhestanian vd. (2016) son y1llarda ZnO nanoyapıların, eşsiz taşıma özellikleri nedeniyle, boya sentezli güneş pili foto-anotlarının oluşumunda oldukça dikkat çektiğini açıklamışlardır. $\mathrm{Bu}$ çalışmada $\mathrm{TiO}_{2}$ tabanlı boya duyarlı güneş hücreleri (DSSC) performans1 korunurken, bir kronoamperometrik metod, rekombinasyon merkezlerini azaltmak ve $\mathrm{TiCl}_{4}$ ön işlemine uygun bir alternatif olarak $\mathrm{ZnO}$ yapıları oluşturmak için gerçekleştirilmiştir. Büyütmeyi kontrol etmek için $\mathrm{ZnO}$ elektrodepozisyonu üzerine polivinil alkolün etkisi ve $\mathrm{ZnO}$ yapıların kristalleşmesi araştırılmıştır. $\mathrm{ZnO} / \mathrm{TiO}_{2}$ tabanlı boya duyarlı güneş pilleri N719 rutenyum boyası kullanılarak oluşturulmuş ve tüm fotovoltaik parametreler karakterize edilmiştir. Akım verimi için uyarıcı fotonun (IPCE) elektrokimyasal empedans spektroskopisi (EIS), dönüşümlü voltametri (CV) ve pil performansinda önemli bir gelişme ile sonuçlanan pil özelliklerini çalışmak için VOC bozunum teknikleri kullanılmıştır (Kouhestanian vd., 2016).

Maleki-Ghaleh vd. (2016) nanoyapılı ZnO ince filmleri elektrodepozisyon işlemiyle flor katkılı kalay oksit (FTO) altlık üzerine sentezlediklerini açıklamışlardır. Filmlerin yapısı ve fotokatalitik davranışı üzerine uygulanan voltajın etkisini incelemişlerdir. Büyütmeler, $70{ }^{\circ} \mathrm{C}$ sicaklikta ve $0.5,0.7,0.9$ ve $1.1 \mathrm{~V}$ farklı potansiyellerde 1000 sn süre ile çinko nitrat ve sodyum nitrat içeren sulu elektrolit çözeltisi kullanılarak gerçekleştirilmiştir. $\mathrm{ZnO}$ filmlerin morfolojisi ve elementel analizi, sirasiyla taramalı elektron mikroskobuyla (SEM) ve enerji ayrımlı x-ışını spekreoskopisi (EDX) kullanarak incelenmiştir. Numunelerin fotokatalitik davranışı bir sodyum sülfat çözeltinde $375 \mathrm{~nm}$ uv-1şını 1şınlaması altında lineer taramalı voltametri, amperometri ve elektrokimyasal impedans testleriyle oluşturulmuştur. Sonuçlar, -1.1 V'ta sentezlenen filmin diğer filmlerle kiyaslandığında en iyi fotokatalitik davranış1 göstermiştir. Nyquist eğrilerinde, daha küçük çaplı yarım dairelerin elektronlar ve iyon transferlerine karşı daha küçük katalizör yüzey direnci gösterdiği açıklanmıştır. FTO altlık üzerine $\mathrm{ZnO}$ kaplı filmlerin EIS grafiklerinin eş değer devreleri verilmiş ve devre özellikleri elektrolit direnci (Rs), $\mathrm{ZnO}$ filminin direnci $\left(\mathrm{R}_{\text {film }}\right), \mathrm{ZnO}$ filminin kapasitans1 $\left(\mathrm{C}_{\text {film }}\right)$ ve çift tabaka direncinden $\left(\mathrm{C}_{\mathrm{dl}}\right)$ oluştuğu ortaya konulmuştur. Elektrik çift tabaka direnç değeri FTO altlık için $9.81 \times 10^{5}$ dan numune için $2.3 \times 10^{3}$ 'e azaldığ 1 ifade edilmiştir. Bu nedenle,
ZnO tabakasının varlığının büyütme yapılmamış olan FTO örneğiyle karşılaştırıldığında FTO yüzeyinde elektron ve iyon transferinin arttırılması üzerine önemli bir etki oluşturduğu açıklanmıştır (Maleki-Ghaleh vd., 2016).

Dabbabi vd. (2019) Nikel (Ni) ve Lantan (La) katk1 maddelerinin, $\mathrm{ZnO}$ ve $\mathrm{SnO}_{2}$ ince filmlerinin yapısal, optik ve elektriksel özellikleri üzerindeki etkileri araştırdıklarını açıklamışlardır. Her iki oksit malzemesi de sprey proliz tekniği kullanılarak, cam altlıklar üzerine büyütülmüştür. Yapısal analiz, tanecik boyutunun katkı1ı $\mathrm{ZnO}$ ve La'dan ziyade $\mathrm{Ni}$ içeren $\mathrm{SnO}_{2}$ için daha iyi arttığını göstermiştir. Optik çalışmalar, Ni ve La katkı1ı ZnO filmlerinin görünür bölgeden kızıl ötesine kadar yaklaşı \% 80-85 oranında yüksek geçirgenlik sergilediğini ortaya çıkarmıştır. La katkılı ZnO, Ni katkılı ZnO ile kıyaslandığında, enerji band değerinde hafif bir artış gözlenmiştir, Ni-katkı1l $\mathrm{SnO}_{2}$ için filmlerin enerji bant değeri $3.46 \mathrm{eV}$ ve La-katk1lı $\mathrm{SnO}_{2}$ filmler için $3.34 \mathrm{eV}$ değerine sahip olduğu ortaya çıkmıştır. Bu da Lakatkılamanın enerji band değerinde bir azalmaya yol açtığı gözlenmiştir Elektriksel özelliklerde oda sicaklığında elektrokimyasal empedans spektroskopisi kullanarak hesaplanmıştır. Tüm katk11ı oksit filmlerin Nyquist grafiklerinin (hem karanlıkta hem de görünür 1 ş1k altında) tek bir yarım daire şeklinde oluştuğu gözlenmiştir. Nyquist grafiklerine fit yapılarak elde edilen eş değer devre parametreleri, sırasıyla seri direnç $\left(\mathrm{R}_{1}\right)$, paralel direnç $\left(\mathrm{R}_{2}\right)$, sabit kapasite ya da sabit faz elementinden ( $\mathrm{C}$ ya da $\mathrm{CPE}_{1}$ ) oluşmaktadır. La:ZnO filmler için karanlı altında $\mathrm{R}_{1}$ : 2.039 $\times 10^{3} \Omega, \mathrm{R}_{2}: 8.720 \times 10^{3} \Omega$ ve $\mathrm{CPE}_{1}: 2.404 \times 10^{-}$ ${ }^{8} \mathrm{~F}$ olarak hesaplanmıştır. Yine La: $\mathrm{ZnO}$ filmler için aydınlık şartlar altında $\mathrm{R}_{1}: 1.922 \times 10^{3} \Omega, \mathrm{R}_{2}$ : $7.101 \times 10^{3} \Omega$ ve $\mathrm{CPE}_{1}$ : $3.607 \times 10^{-8} \mathrm{~F}$ olarak belirlenmiştir. Karanlık şartlar altında Ni:ZnO filmler için $\mathrm{R}_{1}$ : $76.705 \times 10^{3} \Omega, \mathrm{R}_{2}: 697.060 \times 10^{3} \Omega$ ve $C$ : $0.112 \times 10^{-8}$ F'dir. Aydınlık şartlar altında $\mathrm{Ni} Z \mathrm{ZnO}$ filmler için $\mathrm{R}_{1}: 57.166 \times 10^{3} \Omega, \mathrm{R}_{2}$ : $112.800 \times 10^{3} \quad \Omega$ ve $\mathrm{C}: 0.848 \times 10^{-8} \quad \mathrm{~F}$ olarak hesaplanmıştır (Dabbabi vd., 2019).

Elektrodepozisyonla büyütülmüş metal-oksit filmler, günümüzde bilinen ve yaygın şekilde kullanılan diğer tekniklere göre pek çok avantajlara sahiptir (Izaki, 1999). Bunlar aşağıdaki gibi sıralanabilir;

$\begin{array}{ll}\text { i. } & \begin{array}{l}\text { filmin yapısı ve kalınlığ } \\ \text { elektrokimyasal } \\ \text { kontrol edilebilir }\end{array} \\ \text { ii. } & \begin{array}{l}\text { istenilen șekillere sahip altlıklar } \\ \text { üzerine tek tip film elde edilebilir }\end{array}\end{array}$




\section{iii. filmler, $100{ }^{\circ} \mathrm{C}$ 'nin altındaki düşük sicaklıklarda altlı üzerine elektrodepozisyon yapılabilir. \\ iv. büyütme hücresi atmosfere açık olduğu için büyütme sırasında katkılama yapılabilir (Demir vd., 2019) \\ v. düşük maliyetlidir \\ vi. elektrodepozisyon, çevre dostu ve düşük risklidir}

$\mathrm{Bu}$ çalışmada, $\mathrm{ZnO}$ geçirgen ince filmler, elektrokimyasal büyütme metodu kullanılarak indiyum kalay oksit (ITO) altlık üzerine büyütülmüştür. Filmlerin yapısal optik özellikleri, sırasıyla X-1şını kırınım (XRD) metodu ve soğurma spektrumu ile incelenmiştir. Yine, $\mathrm{ZnO}$ ince filmlerin korozyon davranışı Elektrokimyasal Empedans Spektroskopi (EIS) ve Tafel teknikleriyle araştırılmıştır. Bu çalışmada temel amaç, korozyonun elektrokimyasal reaksiyonlardan kaynaklanmasindan dolay1 korozyon süreçlerini incelemek ve malzemenin yapısında meydana gelen değişiklikleri araştırmaktır. Çünkü EIS, sabit bir potansiyelde tutulan elektrokimyasal bir ara yüzü karakterize etmek için kullanılır. EIS, kaplanan malzemelerde batarya araştırması, elektrot kinetiği araştırması ve endüstriyel elektroliz çalışmalarında kullanılan güçlü bir araçtır. $\mathrm{Bu}$ çalışmada hazırlanan nanoyapılı $\mathrm{ZnO}$ ince filmlerin detaylı yapısal, optik ve morfolojik analizleri nedeniyle malzeme bilimi üzerine çalışan çoğu araştırmacı için oldukça önemli olduğu düşünülmektedir. Yukarıda belirtilen nedenlerden dolayı makalede, $\mathrm{ZnO}$ ince filmlerin korozyon davranıșının araştırılması detaylı bir şekilde incelenmiştir. Sonuç olarak, yariiletken malzemeler ve cihazlar üzerine çalışan araştırmacılar için, yıllar sonra bile malzemelerin korozyon davranışının önemini yitirmeyeceği düşünülmektedir.

\section{Materyal ve Yöntem}

$\mathrm{ZnO}$ geçirgen ince filmler ITO altlik (SigmaAldrich firmasindan temin edilen ve $15-25 \Omega . \mathrm{cm}$ sahip ) üzerine $0.05 \mathrm{M} \mathrm{Zn}\left(\mathrm{ClO}_{4}\right)_{2}$ ve $0.1 \mathrm{M}$ $\mathrm{Li}\left(\mathrm{ClO}_{4}\right)$ kullanılarak hazırlanan DMSO çözeltisinde, $-1.0 \mathrm{~V}$ katodik potansiyelde, 1 saatlik sürede ve $130^{\circ} \mathrm{C}$ 'de büyütülmüștür (Tekmen vd., 2010). Büyütmeleri gerçekleştirmek için hazırlanan çözeltinin, pH'1 6 olarak ölçülmüş, Şekil 1(a)'da görüldüğü gibi, ince filmlerin elektrokimyasal büyütülmesi ve ölçümleri Gamry Reference 600 Potentiostat / Galvanostat cihazı kullanılarak gerçekleştirilmiştir. Büyütmeler $\mathrm{Ag} / \mathrm{AgCl}_{2}$ referans elektrot, $\mathrm{Zn}$ karşıt elektrot ve
ITO çalışma elektrodu olmak üzere geleneksel üç elektrotlu sistem kullanılarak yürütülmüştür. Büyütme öncesinde, ITO altlıklar özel temizleme prosedürüne uygun bir şekilde temizlenmiş ve daha sonra azot gazıyla kurutularak $300{ }^{\circ} \mathrm{C}$ ' de 30 dk azot gazı ortamında tavlanmıştır. $\mathrm{ZnO}$ geçirgen ince filmler XRD, soğurma, EIS ve Tafel ölçüm teknikleri ile yapısal, optik ve korozyon özellikleri araştırılmıştır. EIS ve Tafel ölçümleri $0.5 \mathrm{M}$ $\mathrm{Na}_{2} \mathrm{SO}_{4}$ sulu çözeltide oda sıcaklığında yürütülmüştür. Nyquist ve Bode analizleri, $0.01 \mathrm{~Hz}$ ile $100 \mathrm{kHz}$ frekans aralığında ve $10 \mathrm{mV}$ AC voltaj şartlarında gerçekleştirilmiştir. Elde edilen ince filmlerin kristal yapısını belirlemek için $\mathrm{x}-1$ şını kırınım (XRD) spektrumları BRUKER D2 Phaser XRD cihazı ile monokromatik $\lambda=1,54059 \AA$ dalgaboyuna sahip $\mathrm{CuK} \alpha$ 1şını üreten $\mathrm{X}$-1şını katod tüpü kullanılmıştır. X-1şını tüpünün gücü 300 watt'dır. Korozyon analizleri Tafel ölçümleri vasitasiyla +0.25 ile $-0.25 \mathrm{~V}$ arasinda $1 \mathrm{mV} / \mathrm{s}$ tarama hızında gerçekleştirilmiştir.

\section{Bulgular ve Tartışma}
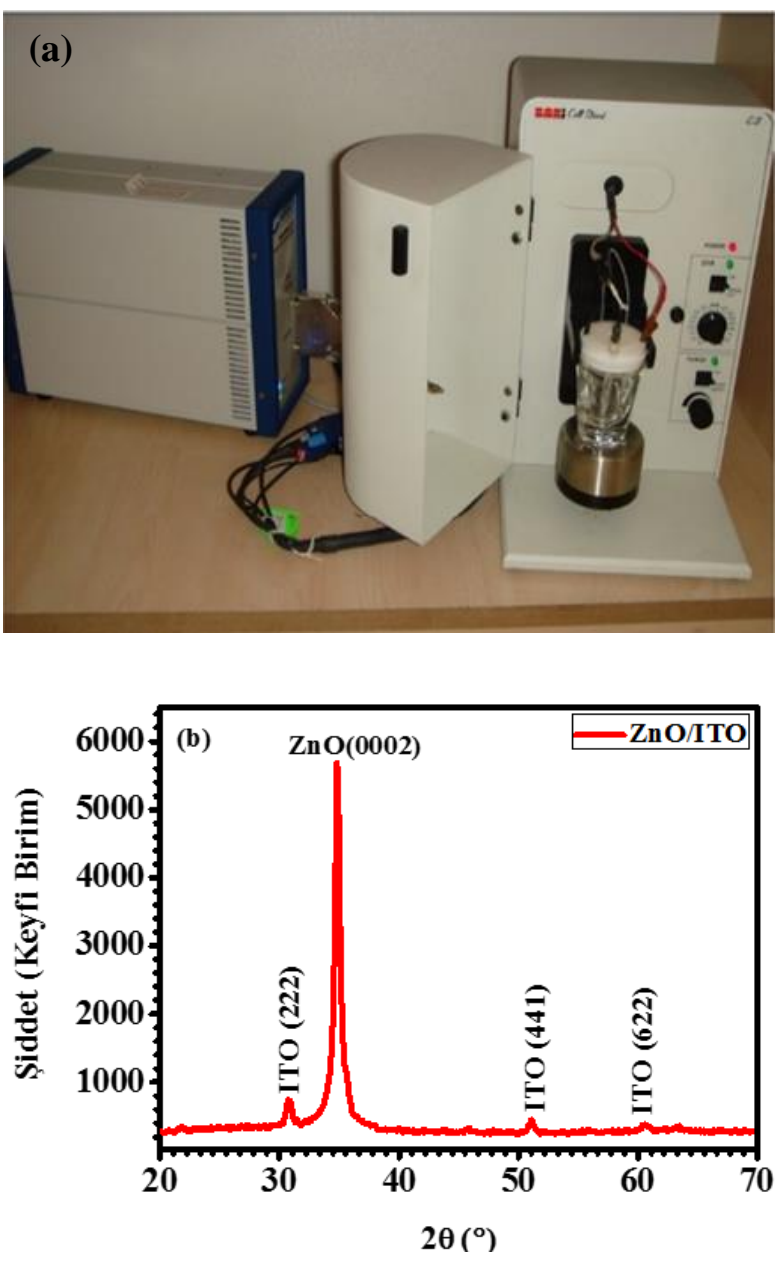

Şekil 1. (a), Elektrokimyasal büyütme tekniği (Gamry Reference 600 Potentiostat / Galvanostat) ve (b), ITO altlik üzerine elektrodeozisyon yapılan $\mathrm{ZnO}$ ince filminin XRD grafiği 
Şekil 1(a) elektrodepozisyonun yapıldı̆̆ geleneksel üç elektrotu sistemi göstermektedir. Şekil 1(b) ise $130{ }^{\circ} \mathrm{C}$ sicaklıkta DMSO'da ITO altlık üzerine elektrodeozisyon yapılan $\mathrm{ZnO}$ ince filminin XRD grafiğini göstermektedir. Şekilde görüldüğü gibi sirasılla (222), (441) ve (622) yönelimlerinde ve yaklaşık $30.36,50.75^{\circ}$ ve $60.34^{\circ}$ açılarındaki ITO altlığın pikleri baskın olmadığ1 için gözükmemektedir. $\mathrm{ZnO}$ ince filmlerin XRD grafiği incelendiğinde (0002) düzleminde ve hegzagonal (wurtzite) yapıya sahip olduğu belirlenmiştir (Asil vd., 2009).

Tablo 1'de büyütülen $\mathrm{ZnO}$ ince filminin XRD grafiğiyle hesaplanan parametreler verilmektedir. XRD ölçümü, elde edilen pikin maksimum şiddetinin gözlendiği açıdaki yarı yükseklikteki genişlik (FWHM) ile alakalıdır. Filmlerin kristal büyüklüğü aşağıda gösterildiği gibi Debye Scherrer eşitliği kullanılarak elde edilmiştir;

$\beta=\frac{\lambda}{t \cos \theta}$

burada $\beta$ XRD'de elde edilen, pikin yarı yükseklik genişliği ve $t$ ise kristal büyüklüğü, $\lambda$ kullanılan X-1şının dalgaboyu ve $\theta$ Bragg açısıdır. Scherrer denklemi normalde polikristal malzemelere uygulanır ve $\mathrm{K}, 0$ ile 1 arasinda değerler alan bir faktördür. Scherrer formülü aşağıdaki şekle dönüşmektedir;

$\beta=\frac{K \lambda}{t \cos \theta}$

$\mathrm{K}$ sabiti $\mathrm{ZnO}$ yarriletkeni için 0.9 değerini almaktadır. Yarı yükseklikteki pik genişliği ile kristal büyüklüğü arasında ters bir ilişki vardır. Piklerin geniş olması kristal boyutunun düşük olduğunu ifade etmektedir ki bu da istenmeyen bir durumdur. Polikristal malzemede pik genişliğinin küçük olması tek kristal bölgelerin büyüklüğü ile açılanabilir ve bu durum gerçekte kristalin kalitesinin yüksek olduğunu göstermektedir.

Şekil 2(a) ve (b), sırasıyla elektrokimyasal büyütme metoduyla DMSO'da büyütülen $\mathrm{ZnO}$ ince filmlerin soğurma karşılık dalgaboyu ve soğurma katsayısına karşılık enerji grafiğini göstermektedir. İnce filmlerin enerji band aralığ Eg, soğurma katsayının karesine $\left(\alpha^{2}\right)$ bağlı enerji(hv) grafiğine fit yapılarak belirlenmektedir. DMSO'da elektrokimyasal olarak büyütülen $\mathrm{ZnO}$ ince filmlerin band aralığı yaklaşık $3.4 \mathrm{eV}$ olarak hesaplanmıştır.
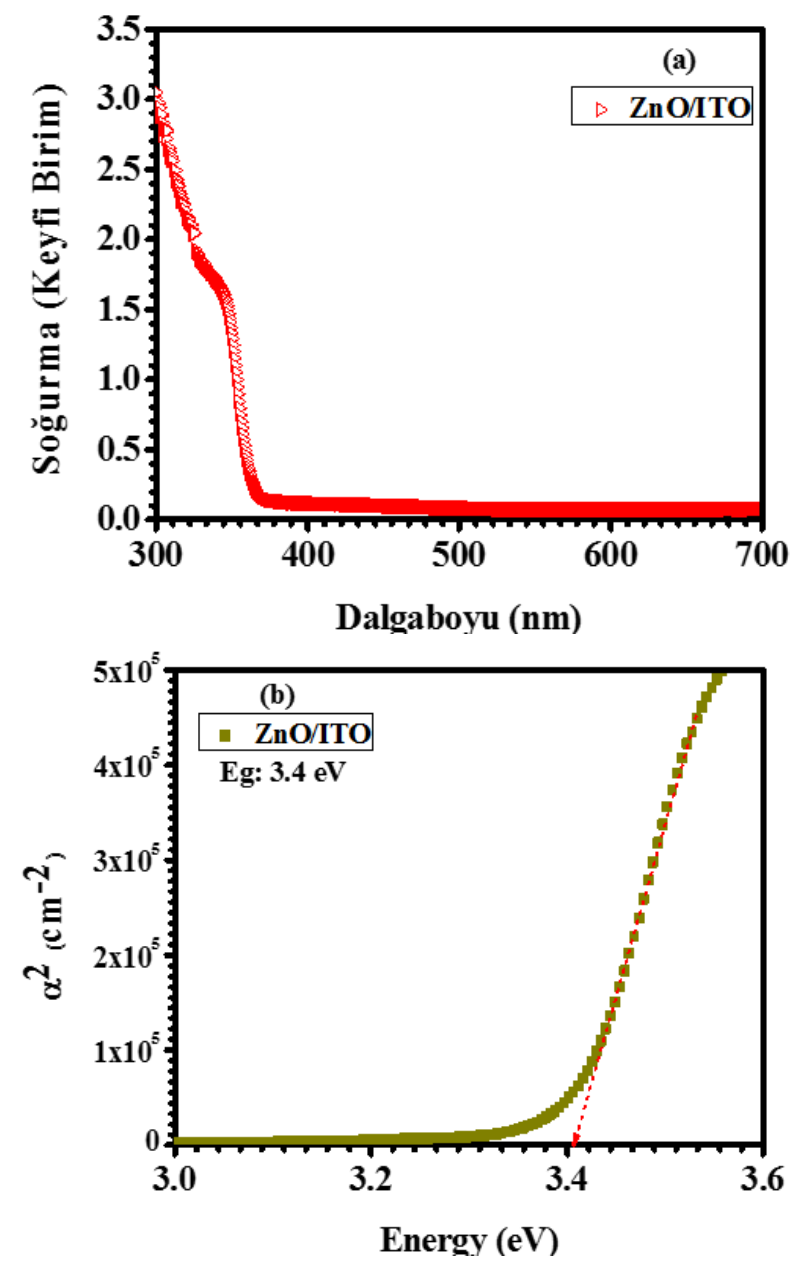

Şekil 2. ITO altlık üzerine DMSO'da $130{ }^{\circ} \mathrm{C}$ sicaklikta büyütülen $\mathrm{ZnO}$ ince filmlerin (a) Soğurmaya karşı dalgaboyu ve (b) $\alpha^{2}$ ye karşı enerji $(h v)$ grafikleri

Şekil 3(a) ve (b) ITO altlık üzerine $130{ }^{\circ} \mathrm{C}$ 'de elektrokimyasal olarak büyütülen $\mathrm{ZnO}$ ince filminin korozyon öncesi ve sonras1 SEM görüntülerini göstermektedir. Korozyon öncesinde elde edilen SEM görüntüsü incelendiğinde altlık üzerine büyütülen $\mathrm{ZnO}$ ince filmi, tüm yüzeye homojen bir şekilde dağılmıştır. Büyütme koşulları, $\mathrm{ZnO}$ ince filmlerinin yüzey görüntülerini etkilemektedir. Elektrolit sicaklığ 1 , büyütme potansiyeli ve $\mathrm{pH}$, büyüyen filmin kalitesini etkilediği gibi yüzey morfolojisini de etkilediği açıkça ortaya çıkmıştır. Ayrıca, elektrodepozisyon işleminin hava akışına açık olduğu oksijen ortamında gerçekleştirilmesi ve kullanılan elektrolit çözeltisinin DMSO ile hazırlanması da yine $\mathrm{ZnO}$ ince filmlerin yüzey morfolojisini ve kristal kalitesini etkilediği anlaşılmaktadır. Yine büyütme potansiyeli ve süresi ITO altlık üzerine elde edilen $\mathrm{ZnO}$ film yapısını ve özelliklerini de etkilemektedir. Çünkü uzun süreli ve sıcaklığa bağlı büyütmeler iyon hareketini etkilediği için $\mathrm{ZnO}$ filminin yapısında bir değişikliğe neden olur ve bu filmin 
stokiyometrisinde önemli bir değişikliğe neden olur. Şekil 3(b)'de görüldüğü gibi, ITO altlık üzerine elde edilen $\mathrm{ZnO}$ ince filminin korozyon sonrası yüzeyinde değişimler söz konusudur. Korozyon sonrası filmin yapısında gözenekli yapı belirginleşmiştir ve filmin yapısı bozulmuştur. ITO altlık üzerine elde edilen $\mathrm{ZnO}$ ince filminin kalınlığ 1 "dokunarak taramalı profilometre" ölçüm sonuçlarına göre yaklaşık olarak $197 \mathrm{~nm}$ olarak belirlenmiştir.

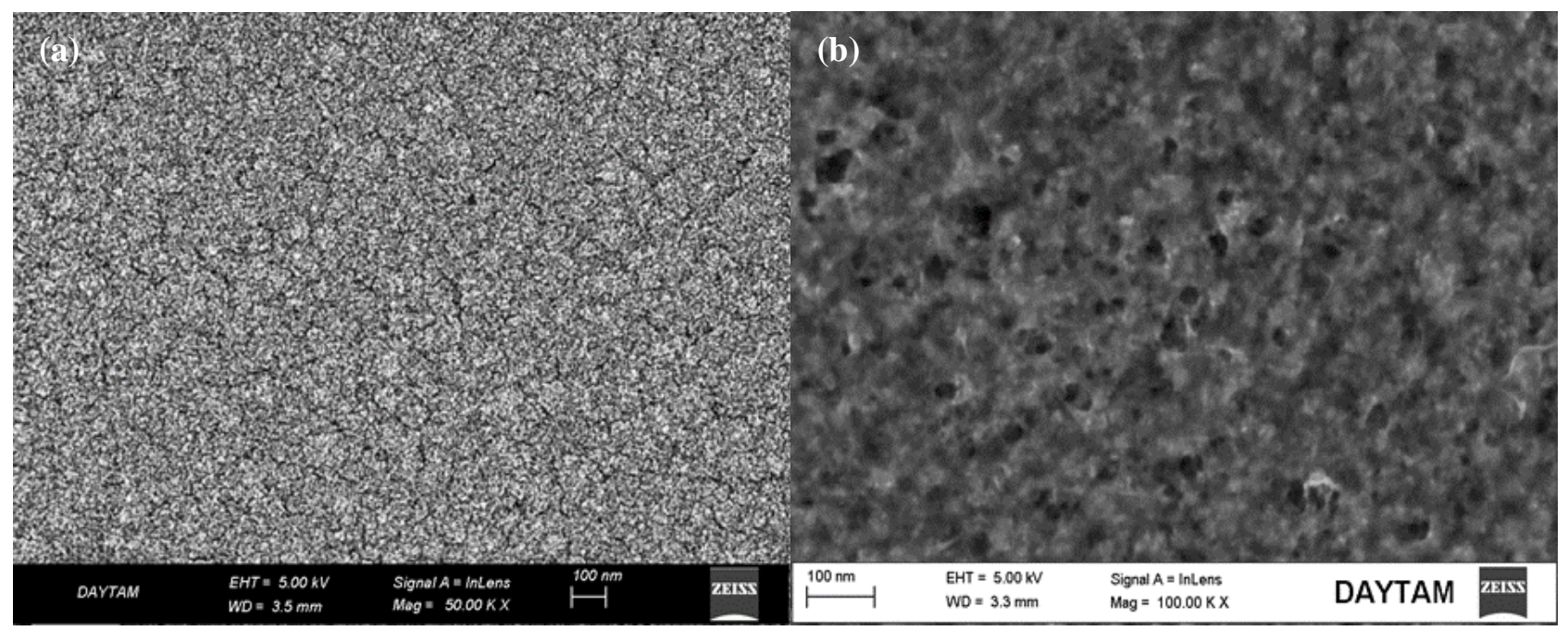

Şekil 3. ITO altlık üzerine elektrokimyasal olarak büyütülen $\mathrm{ZnO}$ ince filminin (a) korozyon öncesi (b) korozyon sonrası SEM görüntüleri

Tablo 1. ITO altlık üzerine elektrodepozisyon yapılan $\mathrm{ZnO}$ ince filminin XRD, EIS ve Tafel parametreleri

\begin{tabular}{|c|c|c|c|c|c|c|}
\hline \multicolumn{7}{|c|}{ XRD Parametreleri } \\
\hline (hkl) & FWHM & Şiddet & $2 \theta\left({ }^{\circ}\right)$ & d- değeri & Tanecik & üklüğğ $(\AA)$ \\
\hline $\mathrm{ZnO}(002)$ & 0.44 & 5721.24 & 34.79 & 2.57 & & .96 \\
\hline \multicolumn{5}{|c|}{ EIS Parametreleri } & \multicolumn{2}{|c|}{ Tafel Parametreleri } \\
\hline Numune & Rs (ohm) & Rp (ohm) & $Q_{\mathrm{dl}}\left(\Omega^{-1} . \mathbf{s} . \mathrm{cm}^{-2}\right)$ & $\mathrm{n}$ & $\mathbf{E}_{\text {kor} \cdot(V)}$ & $\mathbf{I}_{\text {kor. }}(\mathrm{A})$ \\
\hline ZnO/ITO & 49.61 & $4.97 \times 10^{6}$ & $6.75 \times 10^{-6}$ & 0.940 & -0.199 & $2.97 \times 10^{-8}$ \\
\hline
\end{tabular}

Şekil 4'te, elektrodepozisyon yapılan $\mathrm{ZnO}$ numunelerinin EIS ölçümlerini göstermektedir. Bilindiği gibi Nyquist eğrisi yük transferi hakkında bilgi vermektedir (Dalvand vd., 2019). Küçük çaplı Nyquist eğrileri daha düşük direnç ve daha hızlı yük geçişi sağlamaktadır (Yilmaz vd., 2019). $\quad \mathrm{ZnO}$ ince filmlerin empedans parametreleri, elde edilen Nyquist eğrisine Kramers Kronig fit yapılarak elde edilen ve Şekil 4 içerisine yerleştirilmiş olan basit bir RC eş değer devresi yardımıyla belirlenmektedir. Burada çözelti direnci (Rs), polarizasyon direnci (Rp) ve sabit faz elemanından (CPE $\left.\mathrm{dl}_{\mathrm{dl}}\right)$ oluşmaktadır. Nyquist eğrisine fit yapılarak elde edilen eş değer empedans parametreleri Rs, $\mathrm{Rp}, \mathrm{CPE}_{\mathrm{dl}}$ ve $\mathrm{n}$ yaklaşık olarak sırasıyla $49.61 \mathrm{ohm}, 4.97 \times 10^{-6}$ ohm, $6.75 \times 10^{-6} \quad \Omega^{-1} . \mathrm{s}^{\mathrm{cm}} \mathrm{cm}^{-2}, \quad 0.940$ olarak hesaplanmıştır. Rs, elektrokimyasal hücrenin empedansında önemli bir parametredir. Geleneksel üç elektrot potantiyostatı, karşıt ve referans elektrotları arasındaki çözelti direncini telafi etmektedir. Ancak çalışma ve referans elektrotları arasındaki çözelti direnci dikkate alınmalıdır. Ayrıca, Rs akım taşındığında yüzey alanına, sicaklığa, iyon tipine ve iyonik konsantrasyona bağlıdır. Bir elektrotun potansiyeli, açık bir devredeki değerinden uzak tutulurken buna elektrotun polarize edilmesidir. Bir elektrot polarize olur ve elektrot yüzeyinden oluşan elektrokimyasal reaksiyonlardan akımın akmasına neden olabilir. Ek olarak, CPE elektrot potansiyeli, sicaklık, iyonik konsantrasyonlar, iyon tipi, oksit katmanları, elektrot pürüzlülüğü ve safsızlık gibi pek çok faktöre bağlı olan elektrot / elektrolit arayüzündeki elektriksel çift tabakanın ideal olmayan kapasitif davranışını modellemek için kullanılmaktadır. CPE'nin empedans değeri aşağıdaki denklemle hesaplanabilir (Çınar Demir, 2020);

$Z_{C P E}=\frac{1}{Q(j \omega)^{n}}$

burada; $Q, \omega, j$ ve $n$, CPE sabiti, açısal frekans ( $\mathrm{rad} / \mathrm{s}$ cinsinden), hayali bir sayıdır ve sirasiyla yüzeyin heterojenliği veya pürüzlülüğünün 
göstergesi olarak kullanılabilen bir CPE üssüdür. n'ye bağlı olarak sabit faz elementi direnci $(n=0$, $\mathrm{Q}=\mathrm{R})$, kapasitansı $(\mathrm{n}=1, \mathrm{Q}=\mathrm{C})$, indüktansı $(\mathrm{n}=$
$-1, \mathrm{Q}=\mathrm{L})$ veya Warburg empedansinı $(\mathrm{n}=0.5, \mathrm{Q}$ $=\mathrm{W})$ temsil etmektedir.

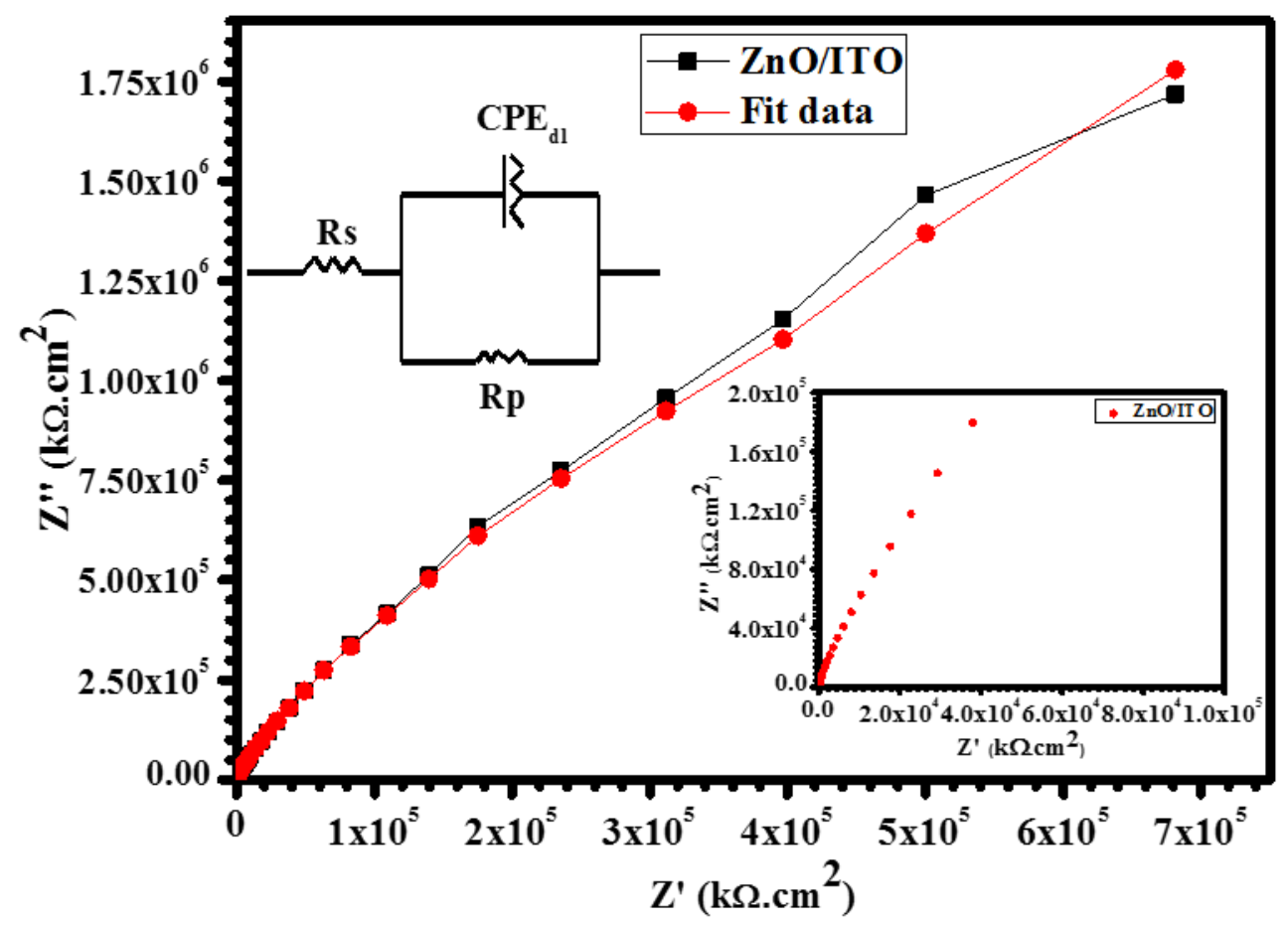

Şekil 4. ITO altlık üzerine elektrodepozisyon yapılan $\mathrm{ZnO}$ geçirgen ince filminin Nyquist grafiği

Daha küçük yük transfer direnci değeri, elektrokimyasal ölçüm sırasında elektrot ve elektrolit arasındaki arayüzlerde etkili bir elektron transferinin gerçekleştiğini göstermektedir. Yüksek elektrolit direnci de bu fikri desteklemektedir. Ek olarak, Nyquist eğrisi, döngü yarıçapının artan frekansla büyüdügünü gösteriyor. $\mathrm{Bu}$ özellik, elektrolitlerin sızmasını engelleyen kararlı bir yap1 oluşumu nedeniyle malzemelerin korozyon direncinde bir gelişme olarak yorumlanabilmektedir. Rp değerinin, malzemenin sergilediği korozyon oranı ile ters orantılı olduğu dikkate alınmalıdır. Böylece, daha yüksek Rp değerinin malzemelerin daha yüksek korozyon direnci anlamına geldiği kolayca söylenebilir. Eşdeğer devrenin basit bir RC devresi olduğu ve yük iletimini önlemek için seçilen elektrolit nedeniyle yük transferinden sorumlu olan paralel direncin çok yüksek olduğu göz önüne alınmalıdır.

Bu çalışmada, EIS analizi ile elde edilen Nyquist eğrilerinin, $\mathrm{ZnO}$ filmlerin korozyon direncindeki artış eğilimine işaret ettiği gösterilmiştir. $\mathrm{Bu}$ durum, pasif film yaklaşımları dikkate alınarak açılanabilir. $\mathrm{Bu}$ modele göre pasif filmde, ZnO'nun kristal yapısına ek katyon boşluğu oluşumu meydana gelebilir. $\mathrm{ZnO}$ ince filmindeki katyonlar, çok yüksek oksidasyon durumlarında oluşur ve katyon boşluklarının enerjisi, oksijen boşluklarından daha yüksektir. Yine, metal-film ve film-çözelti arayüzlerinde kusurların oluşması daha da yaygındir. Elektrokimyasal reaksiyonlarda hem metal-film hem de filmçözeltisi arasında pozitif ve negatif kusur oluşumu çok farklı değildir (Vazquez ve Gonzalez, 2007). Aslında, pasif filmler, altlık yüzeyinde kendiliğinden oluşan, ekstra kimyasal reaksiyonu önleyen ultra ince film anlamina gelmektedir. Elde edilen sonuçlara göre, tane büyüklüğünün azaltılmasının, elektronların tane sinırları yakınındaki elektronların aktivitesinde bir artışa yol açabileceği, buna bağlı olarak yüzeyin daha reaktif olacağı ve dolayısıyla $\mathrm{ZnO}$ 'nun yüzeyinde stabil bir pasif film oluşturacağı tahmin edilmektedir. $\mathrm{Bu}$ olgunun literatürdeki bazı çalışmalarla da uyumlu olduğu görülmektedir (Balakrishnan vd., 2008; Ralston ve Birbilis, 2010).

Şekil 5, ITO üzerine elektrodepozisyon yapılan $\mathrm{ZnO}$ ince filmlerinin Bode ve faz açısı grafiklerini göstermektedir. Bu grafiklerden görüldüğü gibi, faz açısı daha yüksek değerlere doğru artmaya meyilli olup, bu durum, $\mathrm{ZnO}$ elektrot üzerinde pasive bir yüzey oluşmasıyla açıklanabilmektedir. Ek olarak, ZnO kaplı elektrotla karşılaştırıldığında faz açısında yüksek değişim gözlenmektedir. Film 
yüzeyinde oluşan pasivasyon, oksit filmlerde, Bode analizinde görülen daha yüksek açılı değişikliklerden kaynaklı olmasıyla açıklanabilir. Ayrıca film ile aşındırıcı elektrolit arasındaki sınırdaki elektriksel çift tabaka ile açıklanmaktadır Yukarıda belirtildiği gibi, Nyquist grafiğinde tek bir kapasitif ark gözlenmiş ve Şekil 5'te yüksek frekanslarda küçük yarım daire gözlenmediği ortaya çıkmıştır. Bode eğrileri ayrıca, ITO altlı̆̆ın sistemin elektrokimyasal tepkisine katkıda bulunduğuna dair bir kanıt olarak görülebilecek tek bir zaman sabiti ortaya koymaktadır. ZnO filmlerin korozyon direncinin büyük olmasında, kaplanan filmlerdeki kusurların ve düzensizliklerin sorumlu olduğu düşünülmektedir (G-Berasategui vd., 2015). Tane boyutu, filmin yapısını önemli ölçüde etkilemektedir ve filmin yapısında farklı değişimlere sebep olmaktadır. Filmin yapısındaki değişim aynı kayma düzlemi üzerinde hareket eden dislokasyonların tane yakınlarına birikerek dislokasyon yığınları oluşturmasına ve dislokasyon yoğunluğunun değişimi ile sonuçlanmaktadit. Büyütme sırasında artan dislokasyon yoğunluğu tane sinırlarının önünde bulunan dislokasyon yığınlarının kaymasına ve diğer bir tane sınırına ulaşarak yapı içerisinde hareketine neden olmaktadır. $\mathrm{Bu}$ da filmin yapısının değişmesine neden olmakta ve film yapısında oluşan kusurlu yapının korozyon direncinin artmasına neden olabileceği düşünülmektedir. Yukarıdaki açıklamalar göz önüne alındığında, $\mathrm{ZnO}$ tabakaları için elde edilen tane sınırlarının varlığıyla ilgili olan dislokasyon yoğunluğu, Bode analizinden elde edilen sonuçların $\mathrm{ZnO}$ yüzeyi ile anlamlı bir şekilde karşılaştırıldığı sonucuna varılabilir.

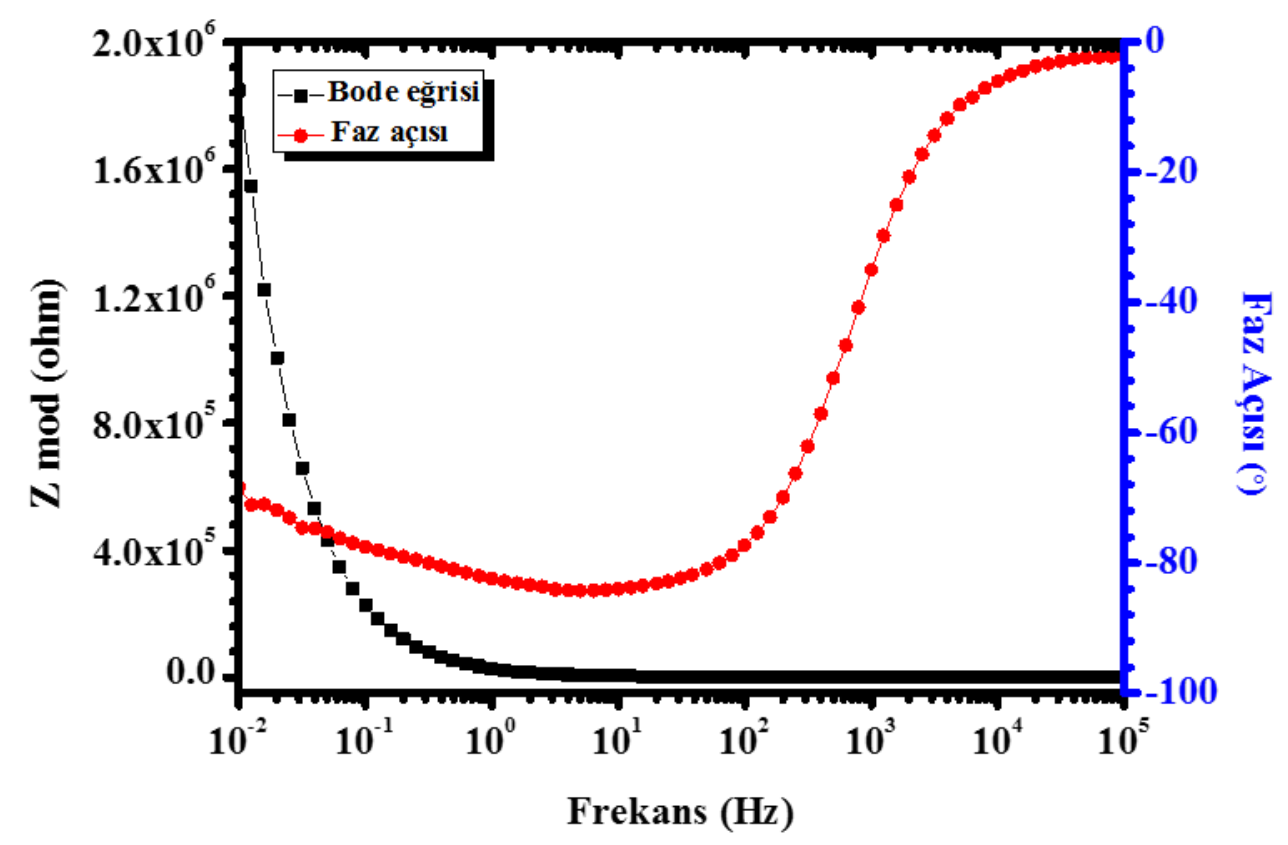

Şekil 5. ITO üzerine elektrodepozisyon yapılan $\mathrm{ZnO}$ ince filmlerinin Bode ve faz açısı grafikleri

Şekil 6, ZnO ince filmlerin Tafel grafiğini göstermektedir. Tafel eğrisine fit yapılarak elde edilen korozyon potansiyeli $\left(\mathrm{E}_{\mathrm{kor}}\right)$ ve korozyon ak1mı ( $\mathrm{I}_{\text {kor }}$ ), sirasiyla $-0.199 \mathrm{~V}$ ve $2.97 \times 10^{-8} \mathrm{~A}$ olarak hesaplanmıştır (Tablo 1'de gösterildiği gibi). Bütün bu ölçümler dikkate alınarak artan korozyon direncinin nedeninin büyütme sırasında oluşan kusurların artmasına bağlı olarak yüzey pasivasyonuna neden olmasıyla açıklanabilir. Korozyon gerçekte anodik ve katodik elektrokimyasal reaksiyonlar arasindaki bir dengeyle belirlenen bir hızda oluşmaktadır. Şekil 6'da gösterildiği gibi, birinci eğri, pozitif voltaj değerlerinde elektronların bu numuneye doğru aktığı ZnO'nun oksitlendiğinin anodik cevabıdır.
Diğer bükülme, bir çözeltinin özelliklerinde (sıklıkla $\mathrm{O}_{2}$ veya $\mathrm{H}^{+}$) azalmanın oluştuğu ve ZnO'dan elektronların dışarı doğru hareket ettiği katodik tepkidir. Bir başka deyişle, Şekil 6'da gözlenen doğrusallık ya da lineerlik suyun katodik indirgeme tepkisi ve hidrojen gazı oluşumunu örnekleyen katodik reaksiyon ile ilişkilidir. Aksine, iki kayda değer karakteristik özelliği olan anodik reaksiyonda bükülme noktalarında gözlenir ve korozyon voltajına kıyasla daha pozitif voltajda eğilmektedir. Bu olay, yüksek anodik aşırı gerilimde korozyon öğeleri tarafından oluşan bir yüzey filminin birikmesiyle sonuçlanan ve çözülmeye yol açan kinetik bariyer etkisine katkida bulunmaktadır. 
Şekil 6'da görüldüğü gibi, bu iki anodik ve katodik reaksiyon dengededir, her bir reaksiyonda elektron akışı dengelenir ve net elektronik akım oluşmaz. Anodik ve katodik reaksiyonlar veya her bir reaksiyondan elektronların akışı dengededir ve net elektrik akımı oluşmaz. Anaodik ve katodik reaksiyonlar, ya tek bir numunede ya da elektriksel olarak bağlı olan iki farklı malzeme üzerinde oluşur. Bu süreç Şekil 6'da detaylıca gözükmektedir. Grafikte dikey eksen voltajdır ve yatay eksen kesin akımın logaritmasıdır. Eğri çizgi ise anodik ve katodik akımların toplamıdır. Numunenin voltajı tarandığında akım ölçülür. Bükülmedeki keskin nokta, logaritmik bir eksenin kullanımından kaynaklanmaktadır. Normalde, sinyal oluşmadan önce akımın istisnai derecede az olduğu nokta burasıdır. Numunenin voltajı, yukarıda belirtilen bu iki reaksiyonun dengede tutulmasıyla açıklanmaktadır. Her yarı reaksiyondan gelen akımın, ZnO'nun elektrokimyasal voltajına bağlı olduğunu detaylı olarak incelenmiştir. Anodik reaksiyonun malzemeye çok fazla elektron saldığını unutulmamalıdır. Artık elektronlar, ZnO'nun voltajını giderek daha negatif değere kaydırmakta ve bu da anodik reaksiyonu yavaşlatmakta ve katodik reaksiyonu da hızlandırmaktadır. Le Châtelier'in ilkesi bu reaksiyon sistemin ilk düzensizliğini ortadan kaldırmaktadır. $\mathrm{Bu}$ olay ZnO'nun korozyon davranışının normal tane büyüklüğünün ultra ince kristalin aralığına indirgenmesiyle normal olarak etkilendiğini açıklayabilir. Film üzerinde yapılan araştırmalar, tane büyüklüğünün azalmasının, elektronların tane sınırlarındaki hareketinin iyileştirilmesinde önemli bir iş üstlendiğini göstermiştir.

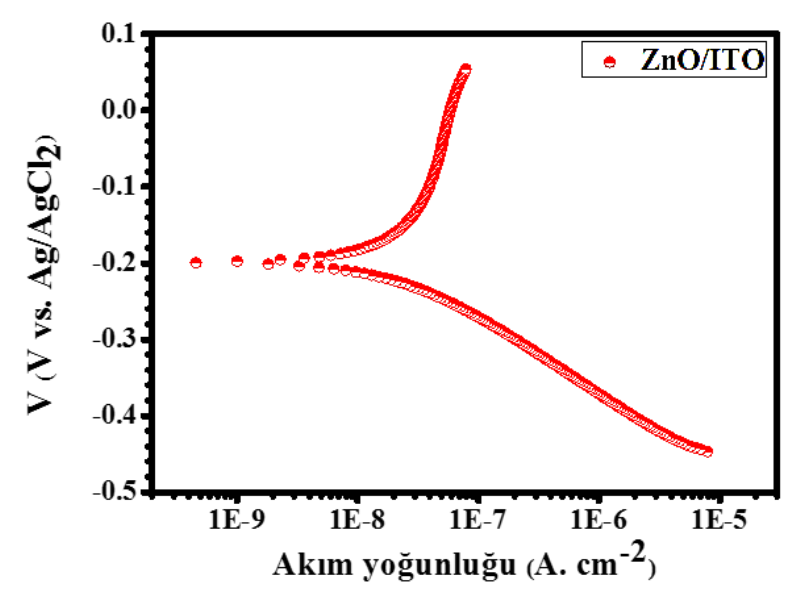

Şekil 6. ITO altlık üzerine elektrodepozisyon yapılan $\mathrm{ZnO}$ ince filminin tafel grafiği

$\mathrm{Bu}$ genişletilmiş elektron hareketi, elektron iş fonksiyonunun azalmasına neden olmaktadır ve yüzey tamamen katı ve kararlı bir pasif filmin hızlı bir şekilde gelişmesine yol açmakta ve pasivasyon kapasitesinde bir artmaya sebep olmaktadır.

\section{Sonuçlar}

$\mathrm{Bu}$ çalışmada, geçirgen $\mathrm{ZnO}$ ince filmler elektrokimyasal büyüme tekniği ile ITO altlık üzerine büyütülmüştür. Filmlerin kalitesi üzerine katodik büyütme potansiyeli, büyütme zaman1, sıcaklık ve pH etkileri araştırılmıştır. Deneysel sonuçlar en iyi kaliteli filmlerin $-1.0 \mathrm{~V}$ katodik büyüme potansiyelinde, 1 saat büyüme zaman1, pH: 6 'da ve $130{ }^{\circ} \mathrm{C}$ sicaklıkta elde edildiğini göstermiştir. XRD analizleri altlık üzerine hazırlanan filmlerin tek kristal faza sahip olduğunu kanıtlamaktadır. Soğurma ölçümleri kullanılarak $\mathrm{ZnO}$ ince filmin band aralığı Eg'nin $3.4 \mathrm{eV}$ olduğu belirlenmiştir. ITO altlık üzerine elektrodepozisyon yapılan $\mathrm{ZnO}$ ince filmlerin korozyon davranışı EIS ve Tafel ölçümleriyle belirlenmiş, Nyquist eğrisine fit yapılarak elde edilen çözelti direnci (Rs), polarizasyon direnci $(\mathrm{Rp})$, sabit faz elementi $\left(\mathrm{CPE}_{\mathrm{dl}}\right)$ ve sabit faz elementi üstel değeri (n) sırasıla $49.61 \Omega$, $4.97 \times 10^{6} \Omega, 6.75 \times 10^{-6} \Omega^{-1}$.s.cm ${ }^{-2}$ ve 0.940 olarak hesaplanmıştır. Tafel eğrisine fit yapılarak, elde edilen korozyon potansiyeli $\left(\mathrm{E}_{\mathrm{kor}}\right) \mathrm{ve}$ korozyon akımı ( $\mathrm{I}_{\text {kor }}$ ), sirasiyla $-0.199 \mathrm{~V}$ ve $2.97 \times 10^{-8} \mathrm{~A}$ olarak elde edilmiştir. Bütün bu çalışmalar göz önünde bulundurularak hazırlanan ince filmlerin yapısındaki korozyon direncinin nedeninin büyütme sırasında oluşan kusurların artışına bağlı olarak yüzey pasivasyonuyla açıklanabilir.

\section{Kaynaklar}

Asil, H., Gur, E., Cinar, K. ve Coskun, C., 2009. Electrochemical Growth of $\mathrm{n}-\mathrm{ZnO}$ onto the $\mathrm{p}$ Type GaN Substrate: p-n Heterojunction Characteristics. Applied Physics Letters, 94, 253501 .

Balakrishnan, A., Lee, B.C., Kim, T.N. ve Pa, B.B., 2008. Corrosion Behaviour of Ultra Fine Grained Titanium in Simulated Body Fluid for Implant Application. Trends Biomaterials and Artificial Organs, 22, 58-64.

Çınar Demir, K., 2020. Corrosion Behavior of Electrodeposited Wo3 Thin Films. Ceramics International, 46, 4358-4364.

Dabbabi, S., Souli, M., Ben Nasr, T., Garcia-Loureiro, A. ve Kamoun, N., 2019. Effects of $\mathrm{Ni}$ and $\mathrm{La}$ Dopants on the Properties of $\mathrm{ZnO}$ and $\mathrm{SnO} 2$ Thin Films: Microstructural, Optical and Impedance Spectroscopy Studies. Journal of Electronic Materials, 49, 1314-1321. 
Dalvand, R., Mahmud, S. ve Seeni, A., 2019. Chemical Sensing Performance of Flower-Like ZnO/PSi Nanostructures via Electrochemical Impedance Spectroscopy Technique. Journal of Electronic Materials, 48, 1604-1611.

Demir, K.C., Demir, E., Yuksel, S. ve Coskun, C., 2019. Influence of Deposition Conditions on Nanostructured InSe Thin Films. Current Applied Physics, 19, 1404-1413.

Fahoume, M., Maghfoul, O., Aggour, M., Hartiti, B., Chraibi, F. ve Ennaoui, A., 2006. Growth and Characterization of $\mathrm{ZnO}$ Thin Films Prepared by Electrodeposition Technique. Solar Energy Materials and Solar Cells, 90, 1437-1444.

Fay, S., Kroll, U., Bucher, C., Vallat-Sauvain, E. ve Shah, A., 2005. Low Pressure Chemical Vapour Deposition of $\mathrm{ZnO}$ Layers forThin-Film Solar Cells: Temperature-Induced Morphological Changes. Solar Energy Materials and Solar Cells, 86, 385-397.

G-Berasategui, E., Bayon, R., Zubizarreta, C., Barriga, J., Barros, R., Martins, R. ve Fortunato, E., 2015. Corrosion Resistance Analysis of Aluminium-Doped Zinc Oxide Layers Deposited by Pulsed Magnetron Sputtering. Thin Solid Films, 594, 256-260.

Gao, Y.F., Nagai, M., Masuda, Y., Sato, F. ve Koumoto, K., 2006. Electrochemical Deposition of $\mathrm{ZnO}$ Film and Its Photoluminescence Properties. Journal of Crystal Growth, 286, 445450.

Izaki, M., 1999. Preparation of Transparent and Conductive Zinc Oxide Films by Optimization of the Two-Step Electrolysis Technique. Journal of the Electrochemical Society, 146, 4517-4521.

Kouhestanian, E., Mozaffari, S.A., Ranjbar, M., SalarAmoli, H. ve Armanmehr, M.H., 2016. Electrodeposited $\mathrm{ZnO}$ Thin Film as an Efficient Alternative Blocking Layer for $\mathrm{TiCl}_{4}$ PreTreatment in $\mathrm{TiO}_{2}$-Based Dye Sensitized Solar Cells. Superlattices and Microstructures, 96, 8294.

Maleki-Ghaleh, H., Shahzadeh, M., Hoseinizadeh, S.A., Arabi, A., Aghaie, E. ve Siadati, M.H., 2016. Evaluation of the Photo-Electro-Catalytic Behavior of Nano-Structured ZnO Films Fabricated by Electrodeposition Process. Materials Letters, 169, 140-143.

Pan, Z.Z., Sun, F.Q., Zhu, X.M., Chen, Z.C., Lin, X., Zheng, Y.J., Zhong, W.Y., Zhuang, Z.F. ve Gu, F.L., 2019. Electrodeposition-Based in Situ Construction of a $\mathrm{ZnO}-O r d e r e d$ Macroporous Film Gas Sensor with Enhanced Sensitivity. Journal of Materials Chemistry A, 7, 12871299.
Pei, L.N., Zhang, B.X., Luo, H., Wu, X.C., Li, G.Q., Sheng, H.C. ve Zhang, L.L., 2019. Electrodeposition of $\mathrm{ZnO}$ Nanoprism-Zn Substituted Hydroxyapatite Duplex Layer Coating for Carbon Fiber. Ceramics International, 45, 14278-14286.

Pellegrino, D., Franzo, G., Strano, V., Mirabella, S. ve Bruno, E., 2019. Improved Synthesis of $\mathrm{ZnO}$ Nanowalls: Effects of Chemical Bath Deposition Time and Annealing Temperature. Chemosensors, 7(2), 18.

Przezdziecka, E., Paradowska, K.M., Lisowski, W., Wierzbicka, A., Jakiela, R., Zielony, E., Gumienny, Z., Placzek-Popko, E. ve Kozanecki, A., 2019. ZnO:Sb MBE layers with Different $\mathrm{Sb}$ Content-Optical, Electronic and Structural Analysis. Journal of Alloys and Compounds, 797, 1163-1172.

Ralston, K.D. ve Birbilis, N., 2010. Effect of Grain Size on Corrosion: A Review. Corrosion, 66(7), 075005-13.

Sharma, V., Prasad, M., Ilaiyaraja, P., Sudakar, C. ve Jadkar, S., 2019. Electrodeposition of Highly Porous ZnO Nanostructures with Hydrothermal Amination for Efficient Photoelectrochemical Activity. International Journal of Hydrogen Energy, 44, 11459-11471.

Taleb, S., Dokhan, N., Zazi, N. ve Chopart, J.P., 2019. Perpendicular Weak Permanent Magnetic Field Effect on the Electrodeposited Nanostructured $\mathrm{ZnO}$ Film and Its Kinetic Corrosion Behavior. Protection of Metals and Physical Chemistry of Surfaces, 55, 781-788.

Tekmen, S., Gur, E., Asil, H., Cinar, K., Coskun, C. ve Tuzemen, S., 2010. Structural, Optical, and Electrical Properties of $n-\mathrm{ZnO} / \mathrm{p}-\mathrm{GaAs}$ Heterojunction. Physica Status Solidi aApplications and Materials Science, 207, 14641467.

Tharsika, T., Thanihaichelvan, M., Haseeb, A.S.M.A. ve Akbar, S.A., 2019. Highly Sensitive and Selective Ethanol Sensor Based on $\mathrm{ZnO}$ Nanorod on $\mathrm{SnO}_{2}$ Thin Film Fabricated by Spray Pyrolysis. Frontiers in Materials, 6(122), 1-9.

Vazquez, G. ve Gonzalez, I., 2007. Diffusivity of Anion Vacancies in $\mathrm{WO}_{3}$ Passive Films. Electrochimica Acta, 52, 6771-6777.

Wang, C., Wang, L.J., Zhang, L., Xi, R., Huang, H., Zhang, S.H. ve Pan, G.B., 2019. Electrodeposition of $\mathrm{ZnO}$ Nanorods onto GaN Towards Enhanced $\mathrm{H}_{2} \mathrm{~S}$ Sensing. Journal of Alloys and Compounds, 790, 363-369. 
Weng, J., Zhang, Y.J., Han, G.Q., Zhang, Y., Xu, L., $\mathrm{Xu}$, J., Huang, X.F. ve Chen, K.J., 2005. Electrochemical Deposition and Characterization of Wide Band Semiconductor ZnO Thin Film. Thin Solid Films, 478, 25-29.

Wittkamper, F., Bikowski, A., Ellmer, K., Gartner, K. ve Wendler, E., 2019. Energy-Dependent RBS Channelling Analysis of Epitaxial ZnO Layers Grown on $\mathrm{ZnO}$ by RF-Magnetron Sputtering. Crystals, 9(290), 1-10.
Xie, J., Imanishi, N., Hirano, A., Takeda, Y., Yamamoto, O., Zhao, X.B. ve Cao, G.S., 2011. Determination of Li-Ion Diffusion Coefficient in Amorphous $\mathrm{Zn}$ and $\mathrm{ZnO}$ Thin Films Prepared by Radio Frequency Magnetron Sputtering. Thin Solid Films, 519, 3373-3377.

Yilmaz, M., Demir, K.C., Turgut, G. ve Aydogan, S., 2019. Electrochemical Impedance Spectroscopy Analysis of $\mathrm{ZnO}$ Films: the Effect of $\mathrm{Mg}$ Doping. Philosophical Magazine Letters, 99, 243-252. 